\title{
Supplementation with the histone deacetylase inhibitor trichostatin A during in vitro culture of bovine embryos
}

\author{
Clara Slade Oliveira ${ }^{2}$, Naiara Zoccal Saraiva ${ }^{2}$, Marcela Maria de Souza ${ }^{2}$, Tatiane de Almeida \\ Drummond Tetzner ${ }^{2}$, Marina Ragagnin de Lima ${ }^{2}$ and Joaquim Mansano Garcia ${ }^{2}$ \\ Department of Preventive Veterinary Medicine and Animal Reproduction, Faculty of Agricultural and Veterinary Sciences, \\ Sao Paulo State University, Access Road Professor Paulo Donato Castellane, Jaboticabal, Brazil
}

Date submitted: 15.07.2010. Date accepted: 13.05.2011

\section{Summary}

\begin{abstract}
Trichostatin A (TSA) is a histone deacetylase inhibitor that induces histone hyperacetylation and increases gene expression levels. The aim of the present study was to establish a suitable condition for the use of TSA in in vitro cultures of bovine embryos, and to determine whether TSA would increase blastocyst rates by improvement of chromatin remodelling during embryonic genome activation and by increasing the expression of crucial genes during early development. To test this hypothesis, 8-cell embryos were exposed to four concentrations of TSA for different periods of time to establish adequate protocols. In a second experiment, three experimental groups were selected for the evaluation of embryo quality based on the following parameters: apoptosis, total cell number and blastocyst hatching. TSA promoted embryonic arrest and degeneration at concentrations of 15, 25 and $50 \mathrm{nM}$. All treated groups presented lower blastocyst rates. Exposure of embryos to $5 \mathrm{nM}$ for $144 \mathrm{~h}$ and to $15 \mathrm{nM}$ for $48 \mathrm{~h}$ decreased blastocyst hatching. However, the terminal deoxynucleotidyl transferase-mediated dUTP nick-end labeling assay (TUNEL) assay revealed similar apoptosis rates and total cell numbers in all groups studied. Although, in the present study, TSA treatment did not improve the parameters studied, the results provided background information on TSA supplementation during in vitro culture of bovine embryos and showed that embryo quality was apparently not affected, despite a decrease in blastocyst rate after exposure to TSA.
\end{abstract}

Keywords: Cattle, Embryonic development, Histone deacetylase inhibition, Histone hyperacetylation, Trichostatin A

\section{Introduction}

Although the in vitro production of bovine embryos has been established since the 1980s (Brackett et al., 1982), the percentage of embryos that reach blastocyst stage is still much lower than that obtained in vivo (Lequarre et al., 2003). The high rates of

\footnotetext{
${ }^{1}$ All correspondence to: Clara Slade Oliveira. UNESPVia de Acesso Professor Paulo Donato Castellane, CEP 14884-900, Jaboticabal, São Paulo, Brazil. Tel: +55 16 32092633/+55 16 97242262. Fax: +55 21 25258804. E-mail: claraslade@gmail.com

${ }^{2}$ Department of Preventive Veterinary Medicine and Animal Reproduction, Faculty of Agricultural and Veterinary Sciences, Sao Paulo State University, Access Road Professor Paulo Donato Castellane, zip code 14884-900, Jaboticabal, Brazil.
}

embryo mortality might be due to developmental block, a phenomenon described in many species that occurs concomitantly with major genome activation (Meirelles et al., 2004). Embryonic arrest during major genome activation occurs in cattle during the transition from the 4 th to the 5 th cell cycle due to the inability to modify the repressive chromatin structure and to activate the transcription of genes that are important for development (Betts \& King, 2001).

Chromatin remodelling is regulated in part by epigenetic modifications, which include posttranslational histone modification. The acetylation of histones is related to an increase in gene expression by permitting the access of transcription factors to DNA (Schubeler et al., 2004). After fertilization, the embryo genome is methylated and genes are expressed at very low levels (Dean et al., 2001). Histone acetylation 
reaches its peak at the time of embryonic genome activation, which coincides with an overall increase of gene expression levels (Maalouf et al., 2008). Histone acetylation is regulated by two main enzymes: histone acetyltransferase, which adds acetyl groups to the histone tail, neutralizing its positive charges and weakening its binding to nucleosomes; and histone deacetylase (HDAC), which removes acetyl groups and causes chromatin compaction and silencing of the DNA segment at that site (Johnstone, 2002). Experiments that use RNAi-mediated reduction of HDAC confirmed the role of this enzyme in histone acetylation and gene expression in blastomeres (Ma \& Schultz, 2008).

Studying bovine embryos produced in vitro, Ikeda et al. (2009) found no effect of the HDAC inhibitor trichostatin A (TSA) administered during in vitro fertilization (IVF) on blastocyst rate, although the drug increased the ratio of inner cell mass cells. However, TSA has been applied successfully to the production of bovine clones in order to increase the efficiency of epigenetic recombination of adult cells in nucleus donor cells (Enright et al., 2003; Wee et al., 2007; Ding et al., 2008), and in embryos immediately after embryo fusion (Ding et al., 2008; Iager et al., 2008). Thus, TSA affects chromatin remodelling by increasing histone acetylation.

The objectives of the present study were to determine an adequate concentration and exposure time of TSA during embryonic genome activation and to evaluate the effects of TSA on the in vitro production of bovine embryos. We tested the hypothesis that TSA would improve blastocyst rates by overcoming chromatin repression.

\section{Material and methods}

\section{Supplements}

Reagents and culture media were purchased from Sigma Chemical Co. unless otherwise stated.

\section{Preparation and selection of oocytes}

Bovine ovaries were collected at a local slaughterhouse and processed within $2 \mathrm{~h}$ after slaughter. The ovaries were washed in saline $\left(37^{\circ} \mathrm{C}\right)$ and follicles that measured 3 to $8 \mathrm{~mm}$ in diameter were aspirated with an 18-gauge needle coupled to a $20-\mathrm{ml}$ syringe. Cumulus-oocyte complexes (COCs) presenting at least three layers of cumulus cells and homogenous cytoplasm were selected under a stereomicroscope. The COCs were washed in HEPES-buffered TCM199 (Gibco BRL) supplemented with 10\% fetal bovine serum (FBS; Cripion, Andradina, Brazil), $16 \mu \mathrm{g} / \mathrm{ml}$ sodium pyruvate, and $83.4 \mu \mathrm{g} / \mathrm{ml}$ amikacin (Instituto Biochimico).

\section{In vitro maturation (IVM)}

Groups of 15 COCs were transferred to $100-\mu$ l droplets of medium that contained sodium bicarbonatebuffered TCM-199 supplemented with 10\% FBS, $1.0 \mu \mathrm{g} / \mathrm{ml}$ follicle-stimulating hormone (FSH) (Follitropin $^{\mathrm{TM}}$, Bioniche Animal Health), $50 \mu \mathrm{g} / \mathrm{ml}$ human chorionic gonadotrophin (hCG; Profasi ${ }^{\mathrm{TM}}$ ), $1.0 \mu \mathrm{g} / \mathrm{ml}$ estradiol, $16 \mu \mathrm{g} / \mathrm{ml}$ sodium pyruvate, and $83.4 \mu \mathrm{g} / \mathrm{ml}$ amikacin. The COCs were covered with sterile mineral oil (Dow Corning Co.) and incubated for $24 \mathrm{~h}$ at $38.5^{\circ} \mathrm{C}$ in an atmosphere of $5 \% \mathrm{CO}_{2}$ in air under saturated humidity.

\section{In vitro fertilization}

After IVM, groups of 25 oocytes were washed twice and transferred to 30- $\mu$ l droplets of TALP-IVF medium supplemented with $0.6 \%$ bovine serum albumin (BSA), $10 \mu \mathrm{g} / \mathrm{ml}$ heparin, $18 \mu \mathrm{M}$ penicillamine, $10 \mu \mathrm{M}$ hypotaurine and $1.8 \mu \mathrm{M}$ epinephrine, and covered with sterile mineral oil. Frozen straws of semen from Nellore bulls were centrifuged on a discontinuous $45 / 90$ Percoll gradient for $5 \mathrm{~min}$ at $3600 \mathrm{~g}$. The pellet was resuspended in $2 \mathrm{ml}$ TALP stock medium and again centrifuged for $5 \mathrm{~min}$ at $3600 \mathrm{~g}$. After centrifugation, $80 \mu \mathrm{l}$ of the medium containing the pellet were collected from the bottom of the tube and homogenized in a conical tube. The final suspension was adjusted to a final concentration of approximately $10^{4}$ live spermatozoa per oocyte. The plates were incubated at $38.5^{\circ} \mathrm{C}$ for $20 \mathrm{~h}$ in an atmosphere of $5 \%$ $\mathrm{CO}_{2}$ in air under saturated humidity.

\section{In vitro culture (IVC)}

After IVF, presumptive zygotes were denuded of cumulus cells by vigorous pipetting and cultured in synthetic oviductal fluid (SOF) medium supplemented with $2.5 \%$ FBS and $5 \mathrm{mg} / \mathrm{ml}$ BSA at $38.5^{\circ} \mathrm{C}$ in an atmosphere of $5 \% \mathrm{CO}_{2}$ in air under saturated humidity. Groups of 15 to 20 presumptive zygotes were cultured in 100- $\mu$ l droplets until the time of treatment with TSA. The cleavage rate, blastocyst development, and blastocyst hatching were evaluated 48 h, 7 days and 9 days after IVF, respectively.

\section{Treatment with trichostatin A}

The embryos were washed and transferred to $100-\mu 1$ droplets of IVC medium supplemented with different concentrations of TSA: 5, 15, 25 and $50 \mathrm{nM}$, for 12, 24, 48 or $144 \mathrm{~h}$. After the determined exposure times, the embryos were transferred to droplets of TSA-free IVC 
medium. One half of the medium was changed every $48-72 \mathrm{~h}$.

\section{Assessment of embryo quality by an apoptosis assay (TUNEL) and determination of total blastocyst cell number}

Blastocysts were evaluated by the terminal deoxynucleotidyl transferase-mediated dUTP nick-end labelling (TUNEL) assay using the In Situ Cell Death Detection Kit (Fluorescein, Roche Applied Science) as described by Paula-Lopes \& Hansen (2002). Blastocysts were incubated with $0.5 \%$ Triton X-100 in phosphate-buffered saline (PBS) for $30 \mathrm{~min}$ at room temperature. Next, the embryos were transferred to the final solution containing $10 \mu \mathrm{l}$ of the enzyme solution (terminal deoxynucleotidyl transferase) and $90 \mu \mathrm{l}$ of the labelling solution (fluorescein-dUTP) and incubated for $1 \mathrm{~h}$ at $38.5^{\circ} \mathrm{C}$, followed by incubation with $50 \mu \mathrm{g} / \mathrm{ml}$ RNase A for $1 \mathrm{~h}$ at room temperature. The nuclei were stained with $10 \mu \mathrm{l} / \mathrm{ml}$ Hoechst 33342 for $10 \mathrm{~min}$ and the blastocysts were washed three times in PBS. The positive control was incubated with $50 \mathrm{IU} / \mathrm{ml}$ DNase for $1 \mathrm{~h}$ before incubation with the final enzyme/dUTP solution. The negative control was incubated without the enzyme. The number of apoptotic cells and total number of nuclei was determined under a fluorescence microscope (Olympus IX-70) at wavelengths of 330$385 \mathrm{~nm}$ (Hoechst 33342) and 420-490 nm (fluorescein).

\section{Statistical analysis}

Differences in blastocyst, apoptosis and hatching rates between groups were analysed by the chisquared $\left(\chi^{2}\right)$ test using the MINITAB software, Release 14.1 (Minitab Inc., State College, PA). The total cell number was analysed by one-way analysis of variance (ANOVA) and means were compared by the Tukey test using GraphPad Prism 4.0 software (GraphPad Prism, Inc.).

\section{Results}

\section{Effect of TSA concentration and time of exposure on blastocyst development}

Three replicates corresponding to 1136 oocytes $(n=$ 58-110 per experimental group) were analysed. First, the adequate concentration and exposure time of TSA during IVC of bovine embryos were determined (Fig. 1).

No difference was observed in the blastocyst rate between 8-cell embryos exposed to $5 \mathrm{nM}$ TSA for 12, 24,48 or $144 \mathrm{~h}$ and the control group $(p>0.05)$. For embryos treated with $15 \mathrm{nM}$ TSA, exposure for $12 \mathrm{~h}$ did not affect blastocyst rate $(p>0.05)$. However,

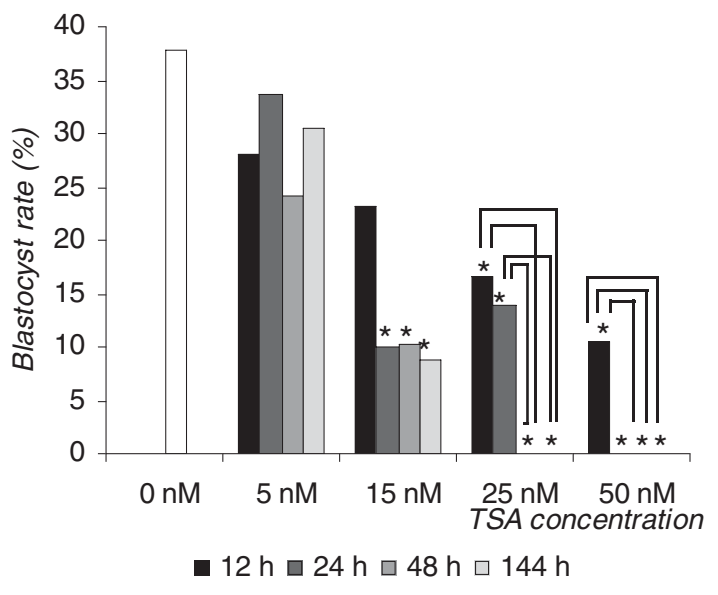

Figure 1 Effects of different concentrations and times of exposure to trichostatin A (TSA) on the development of bovine embryos. In vitro culture medium was supplemented $70 \mathrm{~h}$ after in vitro fertilization (IVF) with $5,15,25$ or 50 nM TSA for 12, 24, 48 or $144 \mathrm{~h}$. Asterisk (*) indicates significant differences compared with the control group and connectors indicate significant differences within the same concentration ( $p<0.05$, chi-squared test).

blastocyst development was lower than in the control group after 24, 48 and $144 \mathrm{~h}$ of treatment with $15 \mathrm{nM}$ TSA $(p<0.05)$. Treatment with $25 \mathrm{nM}$ TSA for 12 or $24 \mathrm{~h}$ reduced the blastocyst rate compared with the control group $(p<0.05)$. Embryos did not reach the blastocyst stage when exposed to $25 \mathrm{nM}$ TSA for longer periods of time (48 or $144 \mathrm{~h})(p<0.05)$. The administration of $50 \mathrm{nM}$ TSA resulted in lower blastocyst development compared with the control group when the embryos were exposed for $12 \mathrm{~h}(p<$ $0.05)$. Embryos did not reach the blastocyst stage when $50 \mathrm{nM}$ TSA was administered for longer periods of time $(24,48$ and $144 \mathrm{~h})(p<0.05)$.

In a second experiment, we carefully investigated the effects of adequate TSA treatment on embryonic development. For this purpose, 1732 cleaved embryos obtained in nine replicates $(n=371-555$ cleaved embryos per experimental group) were exposed to $5 \mathrm{nM}$ for $48 \mathrm{~h}, 15 \mathrm{nM}$ for $48 \mathrm{~h}$, and $5 \mathrm{nM}$ for $144 \mathrm{~h}$. All of the TSA concentrations tested promoted a decrease in blastocyst rate (Table 1).

\section{Effects of TSA on blastocyst hatching}

Five replicates corresponding to 418 blastocysts ( $n=$ 68-159 per experimental group) were analyzed. Treatment with $5 \mathrm{nM}$ TSA for $48 \mathrm{~h}$ had no effect on the percentage of blastocyst hatching $(p<0.05)$ (Table 2). However, TSA promoted a decrease in blastocyst hatching at concentrations of $15 \mathrm{nM}$ applied for $48 \mathrm{~h}$ and of $5 \mathrm{nM}$ applied for $144 \mathrm{~h}(p<0.05)$. 
Table 1 Effects of supplementation of in vitro culture medium with trichostatin A on the development of bovine embryos (Experiment 2)

\begin{tabular}{lcc}
\hline TSA & $\begin{array}{c}\text { Cleaved embryos } \\
n(\%)\end{array}$ & $\begin{array}{c}\text { Blastocysts } \\
n(\%)\end{array}$ \\
\hline 0 (control) & $433(85.91)$ & $193(44.57)^{a}$ \\
$5 \mathrm{nM} \mathrm{48} \mathrm{h}$ & $371(81.89)$ & $135(36.38)^{b}$ \\
$15 \mathrm{nM} \mathrm{48} \mathrm{h}$ & $555(83.33)$ & $119(21.44)^{c}$ \\
$5 \mathrm{nM} \mathrm{144} \mathrm{h}$ & $373(82.15)$ & $92(24.66)^{c}$ \\
\hline
\end{tabular}

Trichostatin A (TSA) was added to the in vitro culture medium $70 \mathrm{~h}$ post-fertilization. The percentage of blastocysts refers to the total number of cleaved embryos.

$a, b, c$ Means followed by the same letter did not differ significantly ( $p<0.05$, chi-square test). Data from nine replicates.

$n=$ number of structures.

Table 2 Effects of supplementation of in vitro culture medium with trichostatin A on blastocyst hatching of bovine embryos

\begin{tabular}{lccc}
\hline TSA & $\begin{array}{c}\text { Hatched } \\
\text { blastocysts }(n)\end{array}$ & $\begin{array}{c}\text { Total } \\
\text { blastocysts }(n)\end{array}$ & $\begin{array}{c}\text { Hatching } \\
\text { rate }(\%)\end{array}$ \\
\hline Control & 96 & 159 & $60.37^{a}$ \\
5 nM 48 h & 55 & 100 & $55.00^{a}$ \\
15 nM 48 h & 35 & 91 & $38.46^{b}$ \\
5 nM 144 h & 15 & 68 & $22.05^{c}$ \\
\hline
\end{tabular}

Trichostatin A (TSA) was added to the in vitro culture medium $70 \mathrm{~h}$ post-fertilization.

$a, b, c$ Means followed by the same letter did not differ significantly ( $p<0.05$, chi-squared test). Data from five replicates.

$n=$ number of structures.

\section{Effects of TSA on total cell number and apoptosis rates of bovine blastocysts}

In this experiment, four replicates corresponding to 91 blastocysts ( $n=16-27$ per experimental group) were analysed. No difference was observed in apoptosis rates or total cell number between the four experimental groups $(p>0.05)$ (Table 3$)$. Therefore, harmful effects on cell cycle or apoptosis were not observed in the experimental groups studied.

\section{Discussion}

The present study provides data regarding the effect of TSA supplementation on bovine preimplantation development. The results showed that even at low concentrations TSA decreased the blastocyst rate, although no harmful effects on embryo quality were observed.

The first cycle of DNA replication after embryonic genome activation is critical for the maximum
Table 3 Effects of supplementation of in vitro culture medium with trichostatin A on apoptosis rate and total cell number of bovine blastocysts

\begin{tabular}{lccc}
\hline TSA & $\begin{array}{c}\text { Blastocysts } \\
(n)\end{array}$ & $\begin{array}{c}\text { Apoptosis } \\
\text { rate }(\%)\end{array}$ & $\begin{array}{c}\text { Total cell } \\
\text { number }\end{array}$ \\
\hline Control & 27 & $5.33 \pm 0.83^{A}$ & $90.18 \pm 5.81^{a}$ \\
$5 \mathrm{nM} 48 \mathrm{~h}$ & 26 & $4.63 \pm 0.75^{A}$ & $81.30 \pm 5.47^{a}$ \\
$15 \mathrm{nM} 48 \mathrm{~h}$ & 22 & $7.72 \pm 0.97^{A}$ & $75.31 \pm 4.29^{a}$ \\
$5 \mathrm{nM} \mathrm{144} \mathrm{h}$ & 16 & $7.93 \pm 1.22^{A}$ & $88.18 \pm 4.73^{a}$ \\
\hline
\end{tabular}

Trichostatin A (TSA) was added to the in vitro culture medium $70 \mathrm{~h}$ post-fertilization. Apoptosis rate and total cell number are reported as the mean \pm standard error.

${ }^{A, a}$ Means followed by the same letter did not differ significantly ( $p<0.05$, one-way analysis of variance (ANOVA) and Tukey post test). Data from four replicates. $n=$ number of structures.

expression of endogenous genes (Aoki et al., 1997). Thus, the time of TSA supplementation chosen in the present experiment was $70 \mathrm{~h}$ post-IVF, when most embryos were in the 8-cell stage. At this time, HDAC inhibition and the consequent increase in gene expression may contribute to overcome chromatin repression.

The results of the first experiment showed that higher concentrations of TSA can be applied for $12 \mathrm{~h}$. However, our aim was to use the drug for longer periods of time when most embryos are in the fourth and fifth cell cycle and to include the remaining cycles of preimplantation development. For this purpose, administration of $5 \mathrm{nM}$ TSA for $48 \mathrm{~h}$ and $144 \mathrm{~h}$ and $15 \mathrm{nM}$ for $48 \mathrm{~h}$ was chosen for Experiment 2.

In a previous study, we demonstrated that male and female embryos respond in a different manner to TSA treatment (Oliveira et al., 2010). Therefore, TSA was administered to in vitro produced embryos fertilized with non-sexed sperm, which produces both male and female embryos in the same drop. The objective was to determine a concentration that would not negatively affect blastocyst development, blastocyst hatching, total cell number or apoptosis.

In conventional systems, IVC increases the proportion of male embryos, which develop faster (Avery et al., 1992) and reach the blastocyst stage more frequently (Xu et al., 1992). It is possible that the negative effect on blastocyst rate observed was due to an altered sex proportion of embryos that developed in the presence of TSA, as male embryos seem to be more sensitive to the negative effects of TSA (Oliveira et al., 2010).

Studies in mice have demonstrated that HDAC plays a role in preimplantation embryonic development by regulating the access of chromatin to transcription factors and consequently decreases gene expression (Ma and Schultz, 2008). HDAC inhibition 
by trapoxin promotes histone hyperacetylation and increases gene transcription in mouse embryos (Aoki et al., 1997). In addition, other HDAC inhibitors have been shown to act as reprogramming agents in cloned bovine embryos (Enright et al., 2003; Wee et al., 2007; Ding et al., 2008; Iager et al., 2008).

Unfortunately, HDAC inhibition does not target specific mechanisms that would result in the increased expression of specific genes. Thus, both beneficial and harmful genes are stimulated and their increased expression activates different pathways that improve or worsen embryonic development. The ideal concentration of TSA in IVC should increase gene expression in such a way that the balance between harmful and beneficial genes is shifted in favour of the latter. This shift was not achieved with the TSA concentrations tested in the present study (5-50 nM). Higher concentrations blocked blastocyst development completely when applied for $24 \mathrm{~h}$ $(50 \mathrm{nM})$ or $48 \mathrm{~h}(25 \mathrm{nM})$.

In conclusion, the most suitable concentration of TSA and period of administration are $5 \mathrm{nM}$ and $48 \mathrm{~h}$, although there was no beneficial effect on the parameters studied. Further studies are needed to investigate embryo implantation and birth, as well as the gene expression profile in TSA treated embryos, as they present histone hyperacetylation and are as viable as control embryos.

\section{Acknowledgements}

The authors thank Roberta Vantini for technical assistance in the IVF laboratory. This study was supported by the State of Sao Paulo Research Foundation (FAPESP), Brazil.

\section{References}

Aoki, F., Worrad, D.M. \& Schultz, R.M. (1997). Regulation of transcriptional activity during the first and second cell cycles in the preimplantation mouse embryo. Dev. Biol. 181, 296-307.

Avery, B., Jorgensen, C.B., Madison, V. \& Greve, T. (1992). Morphological development and sex of bovine in vitrofertilized embryos. Mol. Reprod. Dev. 32, 265-70.

Betts, D.H. \& King, W.A. (2001). Genetic regulation of embryo death and senescence. Theriogenology 55, 171-91.

Brackett, B.G., Bousquet, D., Boice, M.L., Donawick, W.J., Evans, J.F. \& Dressel, M.A. (1982). Normal development following in vitro fertilization in the cow. Biol. Reprod. 27, 147-58.

Dean, W., Santos, F., Stojkovic, M., Zakhartchenko, V., Walter, J., Wolf, E. \& Reik, W. (2001). Conservation of methylation reprogramming in mammalian development: aberrant reprogramming in cloned embryos. Proc. Natl. Acad. Sci. USA 98, 13734-38.
Ding, X., Wang, Y., Zhang, D., Wang, Y., Guo, Z. \& Zhang, Y. (2008). Increased pre-implantation development of cloned bovine embryos treated with 5-aza-2'-deoxycytidine and trichostatin A. Theriogenology 70, 622-30.

Enright, B.P., Kubota, C., Yang, X. \& Tian, X.C. (2003). Epigenetic characteristics and development of embryos cloned from donor cells treated by trichostatin A or 5-aza2'-deoxycytidine. Biol .Reprod. 69, 896-901.

Iager, A.E., Ragina, N.P., Ross, P.J., Beyhan, Z., Cunniff, K., Rodriguez, R.M. \& Cibelli, J.B. (2008). Trichostatin A improves histone acetylation in bovine somatic cell nuclear transfer early embryos. Cloning Stem Cells 10, 37179.

Ikeda, S., Tatemizo, A., Iwamoto, D., Taniguchi, S. \& Hoshino, Y. (2009). Enhancement of histone acetylation by trichostatin A during in vitro fertilization of bovine oocytes affects cell number of the inner cell mass of the resulting blastocysts. Zygote 17, 209-15.

Johnstone, R.W. (2002). Histone-deacetylase inhibitors: novel drugs for the treatment of cancer. Nat. Rev. Drug. Discov. 1, 287-99.

Lequarre, A.S., Marchandise, J., Moreau, B., Massip, A. \& Donnay, I. (2003). Cell cycle duration at the time of maternal zygotic transition for in vitro produced bovine embryos: effect of oxygen tension and transcription inhibition. Biol. Reprod. 69, 1707-13.

Maalouf, W.E., Alberio, R. \& Campbell, K.H.S. (2008). Differential acetylation of histone $\mathrm{H} 4$ lysine during development of in vitro fertilized, cloned and parthenogenetically activated bovine embryos. Epigenetics 3, 199-209.

Ma, P. \& Schultz, R.M. (2008). Histone deacetylase 1 (HDAC1) regulates histone acetylation, development, and gene expression in preimplantation mouse embryos. Dev. Biol. 319, 110-20.

Meirelles, F.V., Caetano, A.R., Watanabe, Y.F., Ripamonte, P., Carambula, S.F., Merighe, G.K. \& Garcia, S.M. (2004). Genome activation and developmental block in bovine embryos. Ann. Reprod. Sci. 82-83, 13-20.

Oliveira, C.S., Saraiva, N.Z., Souza, M.M., Tetzner, T.A.D., Lima, M.R. \& Garcia, J.M. (2010). Effects of histone hyperacetylation on the preimplantation development of male and female bovine embryos. Reprod. Fertil. Dev. 22, 1041-8.

Paula-Lopes, F.F. \& Hansen, P.J. (2002). Apoptosis is an adaptive response in bovine preimplantation embryos that facilitates survival after heat shock. Biochem. Biophys. Res. Commun. 295, 37-42.

Schubeler, D., Macalpine, D.M., Scalzo, D., Wirbelauer, C., Kooperberg, C., Van Leeuwen, F., Gottschling, D.E., O'Neil, L.P., Turner, B.M., Delrow, J., Bell, S.P. \& Groudine, M. (2004). The histone modification pattern of genes revealed through genome-wide chromatin analysis of a higher eukaryote. Genes Dev. 18, 1263-71.

Wee, G., Shim, J.J., Koo, D.B., Chae, J.I. \& Lee, K.K. (2007). Epigenetic alteration of the donor cells does not recapitulate the reprogramming of DNA methylation in cloned embryos. Reproduction 134, 781-87.

Xu, K.P., Yadav, B.R., King, W.A. \& Betteridge, K.J. (1992). Sex-related differences in developmental rates of bovine embryos produced and cultured in vitro. Mol. Reprod. Dev. 31, 249-52. 